\title{
Zekerheid in de waarschijnlijkheidsleer ${ }^{*}$
}

\author{
Sylvia Wenmackers
}

In het focusartikel bespreekt Jeanne Peijnenburg een discussie tussen C.I. Lewis en Hans Reichenbach over de vraag of zinvolle uitspraken over waarschijnlijkheid zekerheid veronderstellen. Lewis meende van wel, Reichenbach meende van niet. Peijnenburg toont aan hoe het standpunt van Reichenbach formeel onderbouwd kan worden. Ze onderzoekt de situatie van een aftelbare keten van elkaar ondersteunende proposities, waarbij de funderende propositie ( $p$, vooraan in de keten) een waarschijnlijkheid kleiner dan één heeft. Haar argument toont aan dat dit er niet noodzakelijk toe leidt dat de waarschijnlijkheid van de uiteindelijk afgeleide doelpropositie (r, achteraan) in de limiet onbepaald of nul zou zijn.

In deze reactie vertrek ik opnieuw van enkele citaten van Lewis. Dan ga ik in op de algemene vraag of het toekennen van een waarschijnlijkheid enige zekerheid veronderstelt. Op basis van deze bespreking stip ik de rol van zekerheid aan in Peijnenburgs argument.

\section{Zekerheid en waarschijnlijkheid bij C.I. Lewis}

Peijnenburg reconstrueert het debat tussen Lewis en Reichenbach in termen van een probabilistische regressie en geeft een tegenvoorbeeld voor de claim dat dit altijd problematisch zou zijn. Een volledig antwoord op Lewis lijkt echter een bredere kijk op de kwestie te vragen. Uit de aangevoerde citaten van Lewis wordt namelijk niet duidelijk of hij enkel op het zo gestelde regressieprobleem doelde, of dat hij (ook) andere zekerheden in gedachten had. ${ }^{1}$

Peijnenburg citeert Lewis (1929: 311): '[E]mpirical knowledge cannot be even probable unless some knowledge is more than probable. The validity of probability-judgments rests upon antecedent general truths which must be certain.' De ruimere context van dit citaat is een bespreking over de rol van het a priori in ons denken. Natuurlijk staat de door Lewis gemaakte aanname, dat a-priori-kennis überhaupt bestaat, juist ter discussie bij de epistemologische vraag of menselijke kennis een fundament nodig heeft. Peijnenburg toont aan dat een funderende propositie met een waarschijnlijkheid kleiner dan één via een eventueel zelfs oneindig lange - keten van voorwaardelijke waarschijnlijkheden toch aanleiding kan geven tot een welbepaalde waarschijnlijkheid (hoger dan een half) van de doelpropositie. De context van het citaat roept echter de vraag op wat voor waarschijnlijkheden dit zijn en of de toekenning ervan op aangenomen zekerheden berust. Hierbij mijn analyse:

(1) De waarschijnlijkheid van doelpropositie $r$ wordt berekend: daarbij steunen we onder meer op de zekerheid van de rekenmethode.

(2) De voorwaardelijke waarschijnlijkheden zijn het resultaat van 'uitvoerig empirisch onderzoek'. Sommige van deze voorwaardelijke waarschijnlijkheden hebben de waarde 0,9 en andere 0,3 . Hierbij valt de kanttekening te maken dat geen enkel (noodzakelijk

\footnotetext{
*Verschenen in Algemeen Nederlands Tijdschrift voor Wijsbegeerte (ANTW) 107 (2): 167-172. DOI: 10.1557/ANTW2015.2.WENM.

${ }^{1}$ Eén bron van ambiguïteit wordt in het focusartikel besproken (in voetnoot 5).
} 
eindig) empirisch onderzoek exact de breuken 9/10 en 3/10 kan opleveren. Hooguit krijgen we een waarde met een bijbehorend betrouwbaarheidsinterval. ${ }^{2}$

(3) Voor de absolute waarschijnlijkheid van funderende propositie $p$ wordt er een waarde

aangenomen (om de methode te kunnen illustreren). Hoe de relevante waarde in een realistisch scenario bepaald zou kunnen worden blijft helaas onvermeld.

De kanttekening bij punt (2) heeft hier enige relevantie omdat het argument van Lewis (1929: 327-328) dat de aanleiding vormt voor Peijnenburgs tegenargument niet louter gaat over de vraag of iets al dan niet waarschijnlijk is, zoals Peijnenburg het reconstrueert (in haar vergelijking 1), maar over de uitspraak dat de waarschijnlijkheid een bepaalde waarde heeft.

De waarschijnlijkheid van de doelpropositie uit punt (3) zou eventueel geschat kunnen worden aan de hand van een steekproef onder de huidige generatie bacteriën. Hiermee kunnen we - althans voor een eindige keten proposities - terugrekenen naar de waarschijnlijkheid van de funderende propositie (via Peijnenburgs vergelijking 16). Aan het einde van sectie 6 wordt echter expliciet gezegd dat hier geen Bayesiaanse aanpak wordt beoogd, waarin de rol van hypothese en evidentie kunnen worden omgewisseld. Nochtans zou deze symmetrie, waarbij je zowel 'vooruit' (van $p$ richting $r$ ) als 'achteruit' (andersom) mag rekenen, mooi aansluiten bij het sleutelbegrip van het coherentisme, namelijk wederzijdse ondersteuning, en Reichenbachs beeldspraak van een netwerk. Het vasthouden aan één volgorde lijkt een residu van de klassieke implicatie of de temporele ordening, maar om tot een echt netwerk te komen en tot wederzijdse ondersteuningsrelaties zijn juist de voorwaardelijke waarschijnlijkheden in beide richtingen (ongeacht de temporele relaties) cruciaal. Ik hoop dat de repliek op dit punt verhelderend zal zijn.

Om duidelijk te maken welk argument ze wil weerleggen, citeert Peijnenburg Lewis (1929: 327-328). Vlak na het geciteerde fragment maakt Lewis echter nog een tweede stipulatie (p. 328): 'provided also that there are some valid principles of probability in general. Wat Lewis precies bedoelde met 'voorafgaande algemene waarheden' (eerder citaat) en 'geldige principes van waarschijnlijkheid in het algemeen' - en of hij daar eigenlijk wel een precies beeld van had - is wellicht niet te achterhalen, maar we kunnen wel evalueren of waarschijnlijkheidstoeschrijvingen inderdaad op zekerheden berusten.

\section{Het zekerheidsprincipe in de klassieke waarschijnlijkheidsrekening}

De klassieke kansrekening kent waarschijnlijkheid één toe aan de uitkomstenruimte. Bij Kolmogorov (1956: 2) vinden we dit terug als een axioma: $P(\Omega)=1$, waarbij $P$ de waarschijnlijkheidsfunctie is en $\Omega$ de verzameling van elementaire uitkomsten. We zullen dit axioma het zekerheidsheidsprincipe noemen (zie ook Hacking 2001: 58). Deze benaming lijkt terecht: de waarschijnlijkheid één lijkt hier gestoeld op een logische zekerheid. Klopt dat ook?

We kunnen waarschijnlijkheden toekennen aan verzamelingen (zoals Kolmogorov en hedendaagse wiskundigen doen) of aan proposities (couranter bij filosofen). Aangezien zowel verzamelingen als proposities een Booleaanse algebra vormen, is dit formeel nagenoeg equivalent. Het is echter juist bij het zekerheidsprincipe dat er een kritiek verschil

\footnotetext{
${ }^{2}$ Deze opmerking is niet beperkt tot waarschijnlijkheidsrekening, maar is van toepassing op elk empirisch resulaat. Als we de notatie 0,9 en 0,3 interpreteren als beduidend tot op één decimaal geldt er een betrouwbaarheidsinterval van $\pm 0,1$.
} 
optreedt. Met proposities kan je het zekerheidsprincipe uitdrukken in termen van een tautologie: bijvoorbeeld $\mathrm{P}(q \vee \neg q)=1$, waarbij $q$ een willekeurige propositie is. ${ }^{3}$ Het analogon met verzamelingen is $\mathrm{P}\left(A \cup A^{\mathrm{C}}\right)=1$, waarbij $A$ een deelverzameling is van $\Omega$ en $A^{\mathrm{C}}$ het complement hiervan binnen $\Omega$.

Samen met de verzamelingen is er echter een praktische onzekerheid binnengeslopen: als $\Omega$ - tegen de theoretische aanname in - niet alle mogelijke uitkomsten bevat, dan correspondeert $\Omega$ niet met een tautologie en vervalt de dwingende reden om hieraan de maximale waarschijnlijkheidswaarde toe te kennen. In theorie is het een absolute zekerheid, terwijl het in de praktijk hooguit een praktische zekerheid betreft. ${ }^{4}$

Meer in het algemeen wijst ook Lewis erop dat a priori's niet leiden tot zekerheden wanneer een theorie wordt toegepast op iets in de werkelijkheid: het is namelijk altijd een onzekere hypothese dat een bepaald theoretisch construct perfect van toepassing is op een concreet fenomeen. (Zie bijvoorbeeld: Lewis 1929: viii, 223 en 292.)

We kunnen elke absolute waarschijnlijkheid horende bij een gebeurtenis $A$ (voorgesteld door een deelverzameling van $\Omega$ ) $\mathrm{P}(A)$ triviaal herschrijven als een voorwaardelijke waarschijnlijkheid door te conditionaliseren op de uitkomstenruimte: $\mathrm{P}(A \mid \Omega)$. Filosofisch is deze ingreep echter niet zonder consequentie. Alle waarschijnlijkheden - ook de zogenaamd absolute - zijn relatief, onder andere ten aanzien van de keuze van $\Omega .{ }^{5}$ Elke waarschijnlijkheidstoekenning laat zich dus lezen als een voorwaardelijke uitspraak: aannemend dat dit alle mogelijkheden zouden zijn (samen met andere aannames), heeft de waarschijnlijkheid voor een welbepaalde gebeurtenis deze waarde. Het kan echter nagenoeg zeker zijn dat niet alle mogelijkheden al gekend zijn. Dit gebeurt met name in de wetenschap, waar algemeen verwacht wordt dat er nog geheel nieuwe mogelijkheden ontdekt zullen worden (bijvoorbeeld op basis van een negatieve meta-inductie). ${ }^{6}$

\section{Zekerheid in het argument van Peijnenburg}

Keren we nu terug naar Peijnenburgs argument. Voor haar resultaat is de volgende aanname doorslaggevend: ook in het geval dat de funderende propositie onjuist blijkt, is er een (weliswaar kleinere) waarschijnlijkheid is dat de afgeleide propositie juist is. De intuïtie dat de uiteindelijke waarschijnlijkheid van de doelpropositie kleiner wordt naarmate de keten langer wordt, heeft ermee te maken dat deze alternatieve mogelijkheid om de afgeleide propositie te realiseren niet in rekening wordt gebracht. Formeel gebeurt dit wel door de wet van de totale kans te gebruiken.

\footnotetext{
${ }^{3}$ Dit vormt bovendien een mooi brugprincipe met klassieke waarheidswaarden.

${ }^{4}$ Om zekerheid te garanderen zou $\Omega$ de grootst mogelijke verzameling moeten zijn, maar zoiets bestaat niet. Andere opties zijn het werken met niet-genormeerde waarschijnlijkheidsfuncties of enkel conditionele waarschijnlijkheidsfuncties als fundamenteel beschouwen.

${ }^{5}$ Voor empirische waarschijnlijkheden is dit punt verwant aan het referentieklasseprobleem.

${ }^{6}$ Voor Bayesianen uit dit probleem zich als volgt: gebeurtenissen of theorieën die niet binnen het bereik van de waarschijnlijkheidsfunctie vallen hebben intuïtief gesproken geen priorwaarschijnlijkheid, maar formeel is deze nul. Hierdoor is het niet mogelijk door updaten een posterior groter dan nul te bereiken. Dit probleem kan worden omzeild door een vorm van Bayesianisme die gebruik maakt van een kapstokhypothese; zie hiervoor Wenmackers \& Romeijn (te verschijnen).
} 
In verzamelingennotatie, waarbij $A$ en $B$ willekeurige deelverzamelingen van $\Omega$ zijn, is de wet van de totale kans:

$$
\mathrm{P}(B)=\mathrm{P}(B \mid A) \mathrm{P}(A)+\mathrm{P}\left(B \mid A^{\mathrm{C}}\right) \mathrm{P}\left(A^{\mathrm{C}}\right) \text {. }
$$

Deze wet steunt op de partitie van $\Omega$ in $A$ en $A^{\mathrm{C}}$, waarvan we aan de unie waarschijnlijkheid één moeten toekennen volgens het zekerheidsprincipe. Het hoeft dan ook niet te verbazen dat Peijnenburg in de volgende stap inderdaad op dit zekerheidsprincipe steunt, want ze gebruikt $\mathrm{P}\left(A^{\mathrm{C}}\right)=1-\mathrm{P}(A)^{7}$

Het lijkt er dus op dat er alsnog zekerheden verondersteld moeten worden alvorens probabilistische rechtvaardiging kan opdoemen. Als tegengewicht sluit ik af met een citaat van Lewis (1929: 23), dat suggereert dat zijn schip anderzijds weleens onder een emergentistische vlag voer: 'There can be no Archimedean point for the philosopher. Proof, he can offer only in the sense of so connecting his theses as to exhibit their mutual support [...]'

\section{Bibliografie}

Hacking, I. (2001) An Introduction to Probability and Inductive Logic. Cambridge: Cambridge University Press.

Kolmogorov, A.N. (1956) Grundbegriffe der Wahrscheinlichkeitsrechnung. Berlijn: Springer. Lewis, C.I. (1929) Mind and the World-Order; Outline of a Theory of Knowledge; herdrukt in 1956 door NY: Dover.

Wenmackers, S., en J.-W. Romeijn (te verschijnen) New theory about old evidence, Synthese DOI:10.1007/s11229-014-0632-x.

\section{Over de auteur}

Sylvia Wenmackers (1980) is als onderzoeksprofessor verbonden aan het Centrum voor Logica en Analytische Wijsbegeerte (CLAW) van het Hoger Instituut voor Wijsbegeerte (HIW) van de KU Leuven (België). Ze studeerde theoretische natuurkunde (UGent, 2002). Ze werkte als assistent in de materiaalfysica aan biosensoren op basis van synthetisch diamant, waarmee ze een doctoraat in de fysica behaalde (UHasselt, 2008). Na een jaar als postdoc verlegde ze haar onderzoek naar de grondslagen van de waarschijnlijkheidsrekening. Op basis van dit onderzoek behaalde ze een tweede doctoraat, ditmaal in de wetenschapsfilosofie (RuGroningen, 2011; cum laude).

\footnotetext{
${ }^{7} \mathrm{P}(\Omega)=1$ volgens het zekerheidsprincipe en $\mathrm{P}(\Omega)=\mathrm{P}(A)+\mathrm{P}\left(A^{\mathrm{C}}\right)$ volgens de basissomregel; dit geeft ons $\mathrm{P}\left(A^{\mathrm{C}}\right)=1-\mathrm{P}(A)$.
} 